\title{
Pseudo-nitzschia simulans sp. nov. (Bacillariophyceae), the first domoic acid producer from Chinese waters
}

\author{
Yang $\mathrm{Li}^{\mathrm{a}, \mathrm{b}, *}$, Chun Xiu Huang ${ }^{\mathrm{a}, \mathrm{b}}$, Guo Shuang $\mathrm{Xu}^{\mathrm{a}, \mathrm{b}}$, Nina Lundholm ${ }^{\mathrm{c}}$, Sing Tung Teng ${ }^{\mathrm{d}}$, \\ Haiyan $\mathrm{Wu}^{\mathrm{e}}$, Zhijun Tan ${ }^{\mathrm{e}}$ \\ ${ }^{a}$ Guangzhou Key Laboratory of Subtropical Biodiversity and Biomonitoring, College of Life Science, South China Normal University, 55 of Zhongshan West \\ Avenue, Guangzhou 510631, PR China \\ ${ }^{\mathrm{b}}$ Guangdong Provincial key Laboratory of Healthy and Safe Aquaculture, College of Life Science, South China Normal University, 55 of Zhongshan West \\ Avenue, Guangzhou 510631, PR China \\ ${ }^{\mathrm{c}}$ Natural History Museum of Denmark, University of Copenhagen, Sølvgade 83S, Copenhagen, Denmark \\ d Faculty of Resource Science and Technology, Universiti Malaysia Sarawak, Kota Samarahan 94300, Malaysia \\ ${ }^{\mathbf{e}}$ Key Laboratory of Testing and Evaluation for Aquatic Product Safety and Quality, Ministry of Agriculture; Yellow Sea Fisheries Research Institute, Chinese \\ Academy of Fishery Sciences, Qingdao 266071, PR China
}

\section{A R T I C L E I N F O}

\section{Article history:}

Received 20 January 2017

Received in revised form 29 June 2017

Accepted 29 June 2017

Available online 12 July 2017

\section{Keywords:}

Domoic acid

China

Pseudo-nitzschia

P. simulans
A B S T R A C T

The genus Pseudo-nitzschia has attracted attention because of production of the toxin, domoic acid (DA), causing Amnesic Shellfish Poisoning (ASP). Pseudo-nitzschia blooms occur frequently in Chinese coastal waters, and DA has been detected in several marine organisms, but so far no Pseudo-nitzschia strains from Chinese waters have been shown to produce DA. In this study, monoclonal Pseudo-nitzschia strains were established from Chinese coastal waters and examined using light microscopy, electron microscopy and molecular markers. Five strains, sharing distinct morphological and molecular features differentiating them from other Pseudo-nitzschia species, represent a new species, Pseudo-nitzschia simulans sp. nov. Morphologically, the taxon belongs to the P. pseudodelicatissima group, cells possessing a central nodule and each stria comprising one row of poroids. The new species is characterized by the poroid structure, which typically comprises two sectors, each sector located near opposite margins of the poroid. The production of DA was examined by liquid chromatography tandem mass spectrometry (LC-MS/MS) analyses of cells in stationary growth phase. Domoic acid was detected in one of the five strains, with concentrations around $1.05-1.54 \mathrm{fg} \mathrm{cell}^{-1}$. This is the first toxigenic diatom species reported from Chinese waters.

(c) 2017 Elsevier B.V. All rights reserved.

\section{Introduction}

The genus Pseudo-nitzschia H. Peragallo is a group of pennate chain-forming diatom species globally distributed in marine waters, and known to produce the toxin domoic acid (DA) (Hasle, 2002). Following an intoxication incident in Canada in 1987, which was found to be caused by P. multiseries (Hasle) Hasle, species of Pseudo-nitzschia attracted attention and considerable progress has

\footnotetext{
* Corresponding author at: College of Life Science, South China Normal University, 55 of Zhongshan West Avenue, Guangzhou 510631, PR China.

E-mail addresses: li-3-yang@163.com (Y. Li), 3127166788@qq.com (C.X. Huang), 835940927@qq.com (G.S. Xu),nlundholm@snm.ku.dk (N. Lundholm), tst861208@hotmail.com (S.T. Teng),wuhy@ysfri.ac.cn (H. Wu), tanzj@ysfri.ac.cn (Z. Tan).
}

been made since then in our understanding of species diversity and toxicology. The number of described species in the genus has increased during the past two decades, and currently comprises 48 , of which 24 are known to produce DA (Teng et al., 2016; Lundholm, 2017).

Identification of Pseudo-nitzschia often requires a combination of different methods, including colony traits and cell shape by light microscopy, frustule ultrastructure by electron microscopy, phylogenetic analyses based on molecular markers, ITS2 secondary structure comparison, sexual mating experiments and physiological traits (reviewed in Lelong et al., 2012; Trainer et al., 2012). Molecular tools have proved the presence of cryptic and pseudocryptic species in the genus (e.g. Amato et al., 2007; Lim et al., 2012; Lundholm et al., 2012; Orive et al., 2013; Percopo et al., 2016; Teng et al., 2016). Most recently described species of Pseudo- 